\title{
Metastatic high-grade neuroendocrine tumor of mandible
}

\author{
Jitender Batra', Chinmay D. Vakade², Sonal Grover², Gyanander Attresh ${ }^{1}$ \\ ${ }^{I}$ Department of Oral and Maxillofacial Surgery, Post Graduate Institute of Dental Sciences, Pt. B.D. Sharma UHS, Rohtak 124001, Haryana, India. \\ ${ }^{2}$ Department of Oral and Maxillofacial Surgery, Bapuji Dental College and Hospital, Davangere 577004, Karnataka, India.
}

Correspondence to: Dr. Jitender Batra, Department of Oral and Maxillofacial Surgery, Post Graduate Institute of Dental Sciences, Pt. B.D. Sharma UHS, Rohtak 124001, Haryana, India. E-mail: dr.batrajatin@gmail.com

\section{A B S T R A C T}

Neuroendocrine tumors of the oral cavity and jaws are exceedingly rare. They include paragangliomas, a melanotic neuroectodermal tumor of infants, small cell carcinomas, and Merckel cell carcinomas. Most have been non-functional in nature. Breast, lung, liver, colon, and prostate are the most common reported primary malignancies which can metastasize to the oral cavity. In most cases, oral metastases involve maxilla and mandible rather than soft tissues. The premolar-molar region is the most common localization. The purpose of this article is to describe a rare case of a high grade neuroendocrine tumor of the mandible which metastasized from the cervix.

Key words: Large/small cell carcinoma of mandible; metastatic tumor/carcinoma to the mandible; neuroendocrine/carcinoid tumor of mandible

\section{INTRODUCTION}

Metastatic lesions to the jaws are known to simulate periodontal and pulpal disease and other radiolucent lesions that can occur in the jaws. Breast, lung, liver, colon, and prostate cancers are the most commonly reported primary malignancies which can metastasize to the oral cavity. ${ }^{[1]}$

Tumors of the neuroendocrine system constitute a heterogeneous group of lesions that vary in origin, location, histological appearance, the degree of differentiation, biologic behavior, functional activity and size but share certain histochemical, immunohistochemical, and ultrastructural characteristics. ${ }^{[2]}$

Neuroendocrine tumors comprise carcinoids, islet cell tumors, medullary carcinomas of the thyroid, mastocytomas, melanomas, Merkel cell tumors of the skin, neurocytomas, oat cell carcinomas, paragangliomas, pinealomas, and pituitary adenomas. ${ }^{[3]}$

The purpose of this article is to describe a rare case of a high-grade neuroendocrine tumor of the mandible which metastasized from the cervix.

\begin{tabular}{|l|l|}
\hline \multicolumn{2}{|c|}{ Access this article online } \\
\hline Quick Response Code: & Website: \\
& http://jcmtjournal.com \\
\cline { 2 - 2 } & \\
\hline
\end{tabular}

\section{CASE REPORT}

A 35-year-old female patient reported with the chief complaint of a swelling in the right lower back region of the jaw for 20 days. Her history revealed a painful tooth in the region which was extracted 1 month earlier, followed by the appearance of swelling few days later. The swelling was initially small in size to start with but gradually progressed to the present size and was associated with loss of sensation on the right side of the lower lip. Medical history revealed that the patient had undergone a hysterectomy for small cell carcinoma of cervix 11 months earlier.

Extra-oral examination revealed a solitary swelling in the right lower third of the face measuring around $2.5 \mathrm{~cm} \times$ $2 \mathrm{~cm}$ in the greatest dimensions, roughly oval in shape with diffuse borders. Right sub-mandibular lymph nodes were palpable, tender, firm-to-hard inconsistency, and fixed.

Intraoral examination revealed the presence of solitary swelling in the right mandibular molar region, measuring $1.5 \mathrm{~cm} \times 1 \mathrm{~cm}$. Vestibular obliteration was evident [Figure 1]. Clinically, teeth number 26, 36, 46, 47 and 48 were

This is an open access article distributed under the terms of the Creative Commons Attribution-NonCommercial-ShareAlike 3.0 License, which allows others to remix, tweak, and build upon the work non-commercially, as long as the author is credited and the new creations are licensed under the identical terms.

For reprints contact: service@oaepublish.com

How to cite this article: Batra J, Vakade CD, Grover S, Attresh G. Metastatic high-grade neuroendocrine tumor of mandible. J Cancer Metastasis Treat 2016;2:127-9

Received: 07-05-2015; Accepted: 29-10-2015. 
missing. Orthopantomograph revealed the presence of an ill-defined, honeycomb radiolucency in the right side of the body of mandible distal to 45 , measuring $4.5 \mathrm{~cm} \times 5 \mathrm{~cm}$, roughly oval in shape [Figure 2]. Occlusal view showed a lingual cortical plate expansion.

Computed tomography scans were taken which demonstrated a destructive lesion in the right mandibular premolar-molar region and exhibited possible muscle infiltration. Further clinical investigations, including full bone scan, abdominal, chest and pelvic examinations, sonar ultrasonography of the abdomen and mammography, showed no space-occupying lesions. Standard hematologic investigations were within normal limits.

Incisional biopsy of the lesion was done and keeping in view the past medical history, a diagnosis of metastatic small cell carcinoma of the mandible was made. Surgery was advised to excise the tumor mass [Figure 3] and a radical right disarticulation hemimandibulectomy along with radical neck dissection on the right side was performed, and reconstruction was done with pectoralis major myocutaneous flap. She recovered well from the

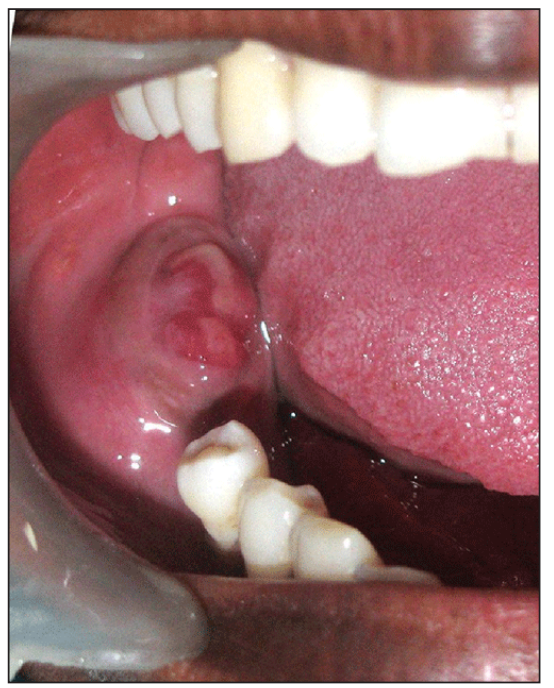

Figure 1: Intraoral photograph of the patient showing the tumor mass at the time of presentation

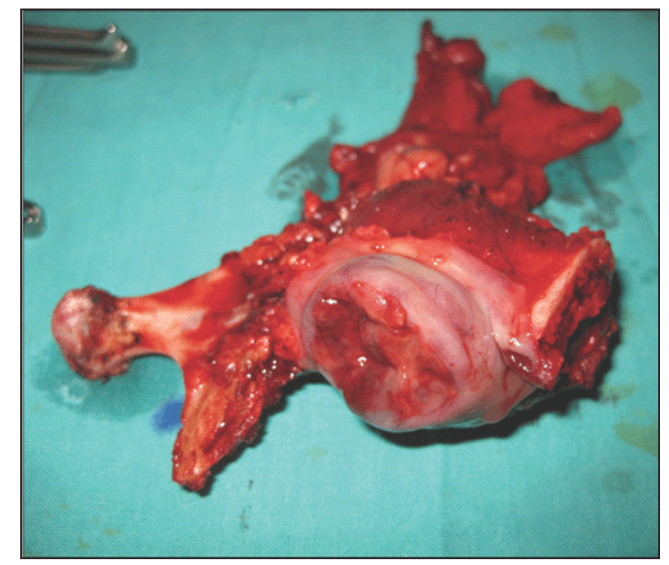

Figure 3: Excised tumor mass with safe margins procedure and was referred to the radiotherapy center for further management. Later, the patient denied a secondary procedure for reconstructive purposes.

The pathological specimen was sent for histopathological examination and revealed tumor cells arranged in a lobular pattern, rosettes-papillary pattern, solid sheets and clusters. These cells had scant eosinophilic cytoplasms with round, polygonal nuclei with stippled chromatin. There were areas of necrosis. These tumor cells were seen infiltrating into the skeletal muscle fibers. Sections from lymph nodes revealed hyperplastic lymphoid follicles and prominent germinal centers. Sinusoids were filled with histiocytes [Figures 4 and 5].

Immunohistochemical studies revealed that the tumor cells were positive for chromogranin, CD56 and synaptophysin, while they were negative for S-100, cytokeratin (CK)-5/6 and p63. Mib-1 labeling index was 50\%. These findings were diagnostic markers of high-grade neuroendocrine carcinoma.

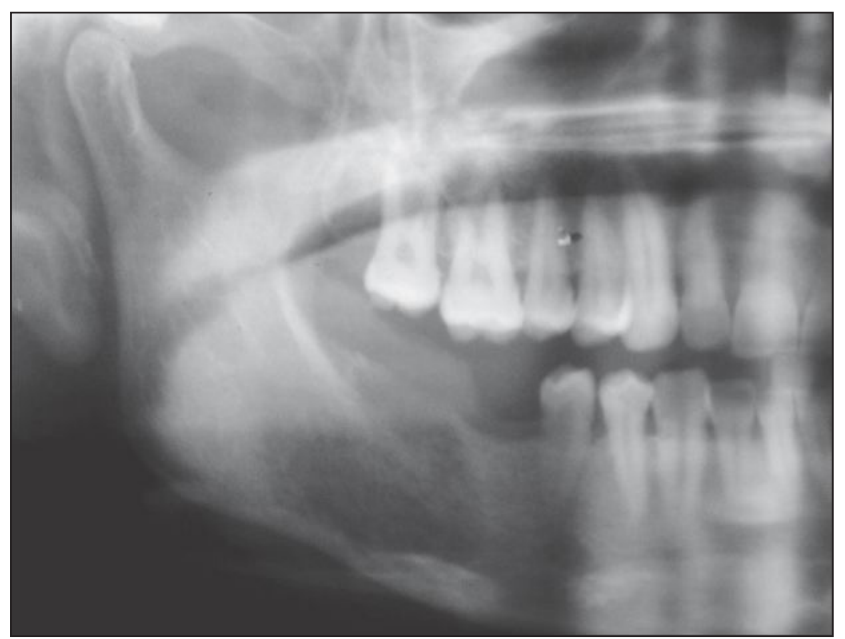

Figure 2: Orthopantomograph showing radiolucent changes in molar region on the right side

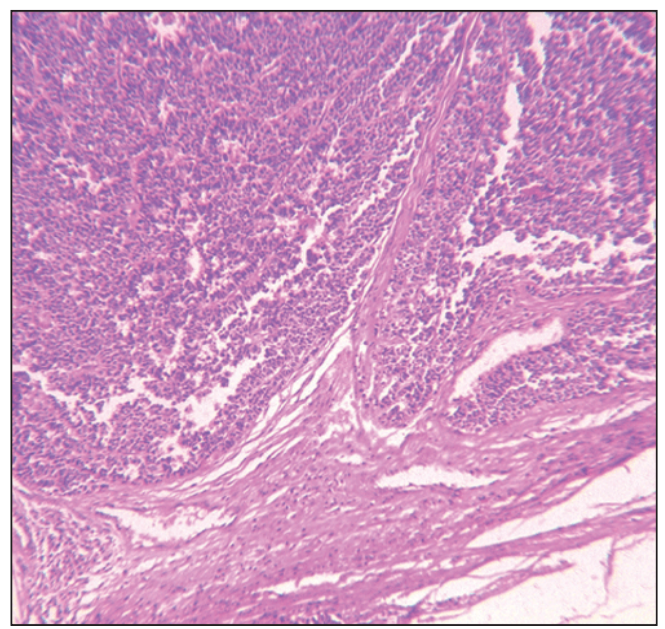

Figure 4: Photomicrograph revealing islands of carcinoma cells arranged in sheets with darkly stained nuclei $(\mathrm{H}$ and $\mathrm{E}, \times 10)$ 


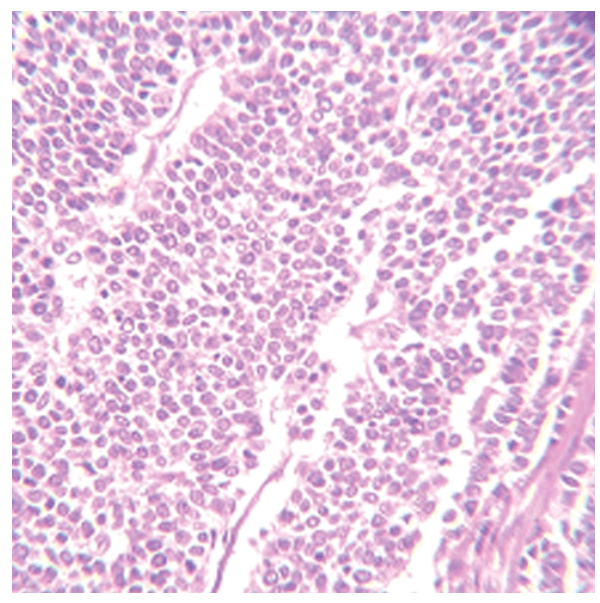

Figure 5: Photomicrograph revealing nuclei with stippled chromatin $(\mathrm{H}$ and $\mathrm{E}, \times 40)$

\section{DISCUSSION}

Primary carcinomas which are reported to metastasize to the jaws include those of the breast, lung, liver, colon and prostate. ${ }^{[1]}$ The primary carcinomas having highest tendency to metastasize are different for both genders. They are as follows in decreasing order: for women, breast followed by carcinomas of the adrenal, colorectum, female genital organs and thyroid; for men, the lung followed by the prostate, kidney, bone and adrenals. ${ }^{[4]}$

It has been reported that most metastatic oral tumors are found in patients in their fifties, sixties and seventies. ${ }^{[4,5]}$ According to Hirshberg et al.,${ }^{[4]}$ metastases to the jawbones have a slight female predilection while metastases to the oral mucosa have a male:female ratio of 1.6:1.

Features that might assist in the assessment of malignancy include the site of origin, depth of invasion, degree of differentiation, functional activity and size of the tumor. ${ }^{[2]}$ The most common symptoms reported in literature are painful swelling, paresthesia, bleeding and increasing tooth mobility along with delayed healing of extraction socket, pathological fracture, masticatory difficulties, trismus, dysphagia, and dyspnea. ${ }^{[6]}$ Paresthesia of the lower lip and the chin was found in our patient. As already reported, this should be considered as ominous sign for metastatic lesions to the mandible, as this signifies deep invasion of the tumor into the bone and involvement of the inferior dental or mental nerves. ${ }^{[7]}$ Mental nerve neuropathy or the "numb chin syndrome", in the absence of other causes, should be considered to be due to mandibular metastases until proven otherwise when seen in a patient with known malignancy. ${ }^{[8]}$

Being very sensitive immune-markers, neuron-specific enolase, and $\mathrm{CK}$ are most commonly used for definitive diagnosis. At present, in addition to ultrastructural studies, immunohistochemical techniques are the most sensitive methods available for the diagnosis of neuroendocrine tumors. ${ }^{[9]}$ Treatment modalities for neuroendocrine carcinomas of the oral cavity have included surgery, multidrug chemotherapy, and radiotherapy, alone or in combination. Currently, well-established treatment protocols do not exist. Surgery alone is inadequate because these tumors tend to progress rapidly and at the time of diagnosis, they are reported to have a metastasis rate of roughly $14-50 \%{ }^{[10]}$

The presentation of a malignant lesion in the orofacial region may be the first indication of the existence of an unknown malignancy at a distant primary site. The presence of altered sensation in the area of the lower jaw and lip/chin region in a patient with a known non-head and neck malignancy should alert the clinician to the possibility of metastatic malignant disease. Appropriate investigations should be carried out to rule out other secondary and manage the case satisfactorily.

\section{Financial support and sponsorship}

Nil.

\section{Conflicts of interest}

There are no conflicts of interest.

\section{REFERENCES}

1. Bircan A, Baykul T, Kapucuoglu N, Ozturk O. Small cell carcinoma of lung with mandible metastasis. Turk Toraks Derg 2008;9:185-7.

2. Coleman H, Kennedy M, Altini M, Crooks J, Tsakiris P. Neuroendocrine (carcinoid) tumor of the mandible: a case report and review of the literature. Oral Surg Oral Med Oral Pathol Oral Radiol Endod 1996;81:74-8.

3. Peters E, Richards A, Hille J, Phillips J. Malignant neuroendocrine tumor presenting in the mandible. Head Neck 1991;13:234-8.

4. Hirshberg A, Leibovich P, Buchner A. Metastatic tumors to the jawbones: analysis of 390 cases. J Oral Pathol Med 1994;23:337-41.

5. Nishimura Y, Yakata H, Kawasaki T, Nakajima T. Metastatic tumours of the mouth and jaws. A review of the Japanese literature. J Maxillofac Surg 1982;10:253-8.

6. Lim SY, Kim SA, Ahn SG, Kim HK, Kim SG, Hwang HK, Kim BO, Lee SH, Kim JD, Yoon JH. Metastatic tumours to the jaws and oral soft tissues: a retrospective analysis of 41 Korean patients. Int J Oral Maxillofac Surg 2006;35:412-5.

7. Bodner L, Sion-Verdy N, Geffen DB, Nash M. Metastatic tumors to the jaws: a report of eight new cases. Med Oral Patol Oral Cir Bucal 2006;11:E132-5.

8. Rim JH, Moon SE, Chang MS, Kim JA. Metastatic hepatocellular carcinoma of gingiva mimicking pyogenic granuloma. J Am Acad Dermatol 2003;49:342-3.

9. Yoshida H, Onizawa K, Hirohata H. Neuroendocrine carcinoma of the tongue: report of a case. J Oral Maxillofac Surg 1995;53:823-7.

10. Devita VT, Hellman S, Rosenberg S. Cancer: Principles and Practice of Oncology. 4th ed. Philadelphia: Lippincott Williams \& Wilkins; 1993. p. $1778-83$. 